\title{
Reducing delirium and cognitive dysfunction after off-pump coronary bypass: A randomized trial
}

Krzysztof Szwed, MD, PhD, ${ }^{a}$ Wojciech Pawliszak, MD, PhD, ${ }^{\mathrm{b}}$ Magdalena Szwed, PhD, ${ }^{\mathrm{a}}$ Marta Tomaszewska, $\mathrm{PhD},{ }^{a}$ Lech Anisimowicz, $\mathrm{MD}, \mathrm{PhD},{ }^{\mathrm{b}}$ and Alina Borkowska, $\mathrm{PhD}^{\mathrm{a}}$

\section{ABSTRACT}

Background: Neuropsychiatric complications of surgical coronary revascularization are inconspicuous but frequent and clinically relevant. So far, attempts to reduce their occurrence, such as the introduction of off-pump coronary artery bypass (OPCAB) grafting method, have not brought the desired results. The aim of this trial was to determine whether using any of the 2 selected modifications of OPCAB could decrease the incidence of these undesired sequelae.

Methods: In this single-center, assessor- and patient-blinded, superiority, randomized controlled trial, 192 patients scheduled for elective isolated OPCAB were randomized to 3 parallel arms. The control arm underwent "conventional" OPCAB with vein grafts. The first study arm underwent anaortic OPCAB (ANA) with total arterial revascularization. The second study arm underwent OPCAB with vein grafts using carbon dioxide surgical field flooding $\left(\mathrm{CO}_{2} \mathrm{FF}\right)$. Outcomes included the incidence of postoperative delirium (PD) and early postoperative cognitive dysfunction (ePOCD).

Results: The incidence of PD was 35.9\% in the control (OPCAB) arm, 32.8\% in the $\mathrm{CO}_{2} \mathrm{FF}$ arm, and $12.5 \%$ in the ANA arm $\left(\chi^{2}[2, \mathrm{~N}=191]=10.17 ; P=.006\right)$. Post hoc tests revealed that the incidence of PD in the ANA arm differed from that in the OPCAB arm (odds ratio [OR], 0.26; 95\% confidence interval [CI], $0.09-0.68 ; P=.002)$. The incidence of $\mathrm{ePOCD}$ was $34.4 \%$ in the OPCAB arm, $28.1 \%$ in the $\mathrm{CO}_{2} \mathrm{FF}$ arm, and $9.5 \%$ in the ANA arm $\left(\chi^{2}[2, \mathrm{~N}=191]=11.58 ; P=.003\right)$. Post hoc tests revealed that the incidence of ePOCD differed between the ANA and OPCAB arms (OR, 0.20; 95\% CI, $0.06-0.58 ; P<.001)$.

Conclusions: Performing ANA significantly decreases the incidence of PD and ePOCD compared with "conventional" OPCAB with vein grafts, whereas $\mathrm{CO}_{2} \mathrm{FF}$ is inconsequential in this regard. These results, which probably reflect decreased delivery of embolic load to the brain in ANA, may have practical applicability in daily practice to improve clinical outcomes. (J Thorac Cardiovasc Surg 2021;161:1275-82)

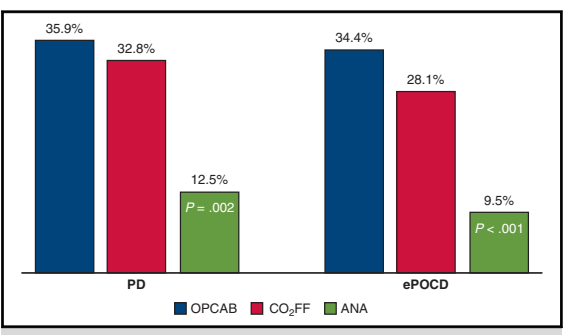

Incidence of neuropsychiatric complications after 3 types of off-pump coronary bypass.

\section{Central Message}

Performing off-pump coronary artery bypass grafting using the anaortic technique results in a 3 -fold reduction in the incidence of postoperative neuropsychiatric complications.

\section{Perspective}

This trial identifies an operating technique that meaningfully reduces the incidence of neuropsychiatric complications after off-pump coronary artery bypass grafting. It has practical applicability in daily clinical practice because using this technique can accelerate patient recovery time and decrease the risk of nosocomial complications, as well as healthcare costs.

See Commentaries on pages 1283 and 1285 .

\footnotetext{
From the Departments of ${ }^{\mathrm{a} C}$ Clinical Neuropsychology and ${ }^{\mathrm{b}}$ Cardiac Surgery, Collegium Medium, Nicolaus Copernicus University, Bydgoszcz, Poland.

This study was partially funded by the Polish National Science Center (Grant 2017/ 01/X/NZ5/01135). This government granting agency had no role in the study design, data collection, data analysis, the decision for publication, or preparation of the research report

Received for publication May 9, 2019; revisions received Aug 16, 2019; accepted for publication Sept 17, 2019; available ahead of print Oct 1, 2019.

Address for reprints: Krzysztof Szwed, MD, PhD, Department of Clinical Neuropsychology, Nicolaus Copernicus University, Collegium Medicum, ul. M. Curie Skłodowskiej 9, 85-094 Bydgoszcz, Poland (E-mail: a.k.szwed@gmail. com).

$0022-5223 / \$ 36.00$

Copyright (c) 2019 by The American Association for Thoracic Surgery

https://doi.org/10.1016/j.jtcvs.2019.09.081
}

Coronary artery bypass grafting is one of the most widely performed major surgeries worldwide. Unfortunately, however, its neuropsychiatric complications remain common even after the introduction of preventative strategies, such as the off-pump coronary artery bypass

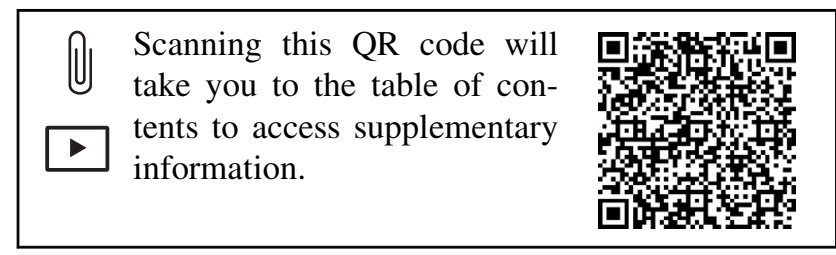




$\begin{aligned} & \text { Abbreviations and Acronyms } \\ & \text { ANA }= \text { anaortic off-pump coronary artery } \\ & \text { bypass } \\ & \mathrm{CI} \text { confidence interval } \\ &= \text { off-pump coronary artery bypass } \\ & \text { with vein grafts using carbon dioxide } \\ & \text { surgical field flooding } \\ & \mathrm{CO}_{2} \mathrm{FF} \text { early postoperative cognitive } \\ & \text { dysfunction } \\ & \text { ePOCD } \text { left anterior descending artery } \\ & \text { LAD } \quad \text { left internal mammary artery to left } \\ & \text { LIMA-LAD } \text { anterior descending artery bypass } \\ & \text { OPCAB }= \text { off-pump coronary artery bypass } \\ & \text { with vein grafts } \\ & \text { OR } \text { odds ratio } \\ & \text { PD } \text { postoperative delirium } \\ & \text { RASS }= \text { Richmond Agitation-Sedation Scale }\end{aligned}$

(OPCAB) grafting method. Considering that up to $30.5 \%$ of post-OPCAB patients develop postoperative delirium (PD) and up to $51.3 \%$ experience early postoperative cognitive dysfunction (ePOCD), identifying an operating technique to reduce these undesired sequelae is a worthwhile goal, ${ }^{1,2}$ especially because treating these complications after onset is difficult, and even their diagnosis is troublesome. It is estimated that without proper screening, up to $84 \%$ of PD cases may go unnoticed because the patient exhibits lethargy rather than agitation. ${ }^{3,4}$ Thus, the PD seen in everyday postoperative clinical practice may only be the tip of the iceberg. Moreover, in contrast to $\mathrm{PD}$, long-term neuropsychological changes are no longer attributed to surgery alone. As a result, study of cognitive decline becomes gradually limited to a dedicated research setting on perioperative brain injury. Consequently, despite their frequency, both PD and ePOCD are often undervalued by clinicians. This is an unfavorable tendency, in view of their association with significantly prolonged recovery time and substantially higher healthcare costs, as well as a 10 -fold increased risk of hospital death and a 5-fold increased risk of nosocomial complications. ${ }^{5,6}$

The objective of this trial was to investigate whether reducing OPCAB's embolic load by using the anaortic (ANA) technique or the practice of carbon dioxide surgical field flooding $\left(\mathrm{CO}_{2} \mathrm{FF}\right)$ could decrease the incidence of postoperative neuropsychiatric complications. The hypothesis was that avoiding a major source of solid microemboli (ie, manipulation of the ascending aorta during proximal vein graft anastomosis) in ANA and reducing the risk of gaseous microemboli formation in $\mathrm{CO}_{2} \mathrm{FF}$ would be of significant benefit compared with "conventional" OPCAB.

\section{MATERIALS AND METHODS \\ Trial Design and Approval}

The CANON trial $\left(\mathrm{CO}_{2}\right.$ Surgical Field Flooding and Aortic No-Touch Off-Pump Coronary Artery Bypass Grafting to Reduce Neurologic Injuries After Surgical Coronary Revascularization) was a single-center, assessor- and patient-blinded, superiority, randomized controlled trial with 3 parallel arms (ClinicalTrials.gov identifier NCT03074604). The study protocol was approved by the local Bioethics Committee (project identifier KB 70/2017) and published in an open-access journal. ${ }^{7}$ The research was completed according to the standards established in the Declaration of Helsinki, and written informed consent was obtained from all subjects.

\section{Participants}

Participants were recruited among patients scheduled for elective isolated OPCAB. Exclusion criteria included a history of neurologic or psychiatric illness, alcohol or drug abuse, use of tranquilizers or antipsychotics, previous cardiac surgery, left ventricular ejection fraction $<31 \%$, and carotid artery stenosis $>70 \%$ in an obligatory preoperative ultrasound. In addition, patients with isolated left anterior descending (LAD) artery stenosis, who could not be randomized due to the current standard of care requiring left internal mammary artery to LAD (LIMA-LAD) bypass in this condition, were also excluded from the trial.

Each candidate meeting the aforementioned criteria was screened with the Mini-Mental State Examination and Hospital Anxiety and Depression Scale to identify preexisting cognitive impairment and mood disorders that could confound the outcomes of this research. Scoring below age- and education-adjusted cutoff scores on the Mini-Mental State Examination resulted in exclusion from the study, whereas scoring $>7$ points on the subscales of the Hospital Anxiety and Depression Scale prompted a psychiatric consultation to objectively evaluate the patient's eligibility.

\section{Study Setting}

Participants were recruited at the Department of Cardiac Surgery, Dr Antoni Jurasz Memorial University Hospital, Bydgoszcz, Poland. This tertiary care center performs more than 400 coronary artery bypass surgeries annually. The OPCAB technique is the standard in all these procedures. During 2017 and 2018, the OPCAB technique was used in $98.65 \%$ of surgical coronary interventions, and there were $0.36 \%$ conversions to on-pump surgery. The postoperative stroke rate after all operations of this type performed in this center during 2017 and 2018 was $1.7 \%$.

\section{Interventions}

Patients were randomized at a 1:1:1 ratio to 1 of 2 study arms (ANA or $\left.\mathrm{CO}_{2} \mathrm{FF}\right)$ or the control arm (OPCAB). To reduce the bias of operator training, only the most experienced surgeons, who had performed at least 500 ANA procedures, participated in this trial. The grafting techniques used in each study arm are described in Appendix E1. All interventions in this trial were performed under the same anesthetic protocol (induction with fentanyl and etomidate; maintenance with propofol, sevoflurane, and fentanyl). When required, postoperative sedation was achieved with dexmedetomidine, and analgesia was provided according to recent guidelines. $^{8}$ All patients were treated before and after surgery in accordance with contemporary European Society of Cardiology Guidelines.

\section{Outcomes}

Early postoperative cognitive dysfunction evaluated on day 7 after surgery, defined as a decline from preoperative performance of $>20 \%$ in more than 2 cognitive domains, was chosen as the primary outcome measure. To assess ePOCD, a battery of well-established neuropsychological 
tests was chosen according to the Statement of Consensus on Assessment of Neurobehavioral Outcomes after Cardiac Surgery. ${ }^{9}$ Details on the selection of ePOCD definition, the design of cognitive test battery, and its administration have been published previously. ${ }^{7}$

The secondary outcome was PD diagnosed with the Confusion Assessment Method for the Intensive Care Unit ${ }^{10}$ within 7 days after surgery. To avoid confounding results with postanesthetic emergence delirium, which is usually of short duration and minimal clinical consequence, ${ }^{11}$ screening for delirium was started 24 hours postoperatively and then performed twice daily at 0800 and 2000 hours for 6 days. Three motoric subtypes of delirium were determined based on the Richmond Agitation-Sedation Scale (RASS) score, ${ }^{12}$ which was measured before each screening. Hyperactive delirium was diagnosed when the RASS score was consistently positive ( +1 to +4$)$, hypoactive delirium was diagnosed when the RASS score was consistently negative or neutral ( -3 to 0$)$, and mixed delirium was diagnosed when the RASS score was alternately positive $(+1$ to +4$)$ and negative or neutral $(-3$ to 0$) .{ }^{13}$ Unresponsive patients (RASS score -5 or -4 ) were excluded from further assessment and defined as comatose.

\section{Sample Size}

The sample size was calculated for the primary outcome based on a previous pilot study that demonstrated a $50 \%$ incidence of ePOCD after $\mathrm{OPCAB}$ and a $50 \%$ reduction in ePOCD after ANA. ${ }^{2}$ Consequently, the expected failure rate was 0.5 in the $\mathrm{OPCAB}$ arm and 0.25 in the ANA arm. With significance set at 0.05 and power set at $80 \%$, the sample size required to detect differences was 58 for each of these arms. There was insufficient evidence for predicting the rate of ePOCD in the $\mathrm{CO}_{2} \mathrm{FF}$ arm, and this arm's sample size was arbitrarily set at 58 , in line with the other study arms. To compensate for any causes of missing data, the sample size was increased by $10 \%$ in each arm, for a total of 192 patients.

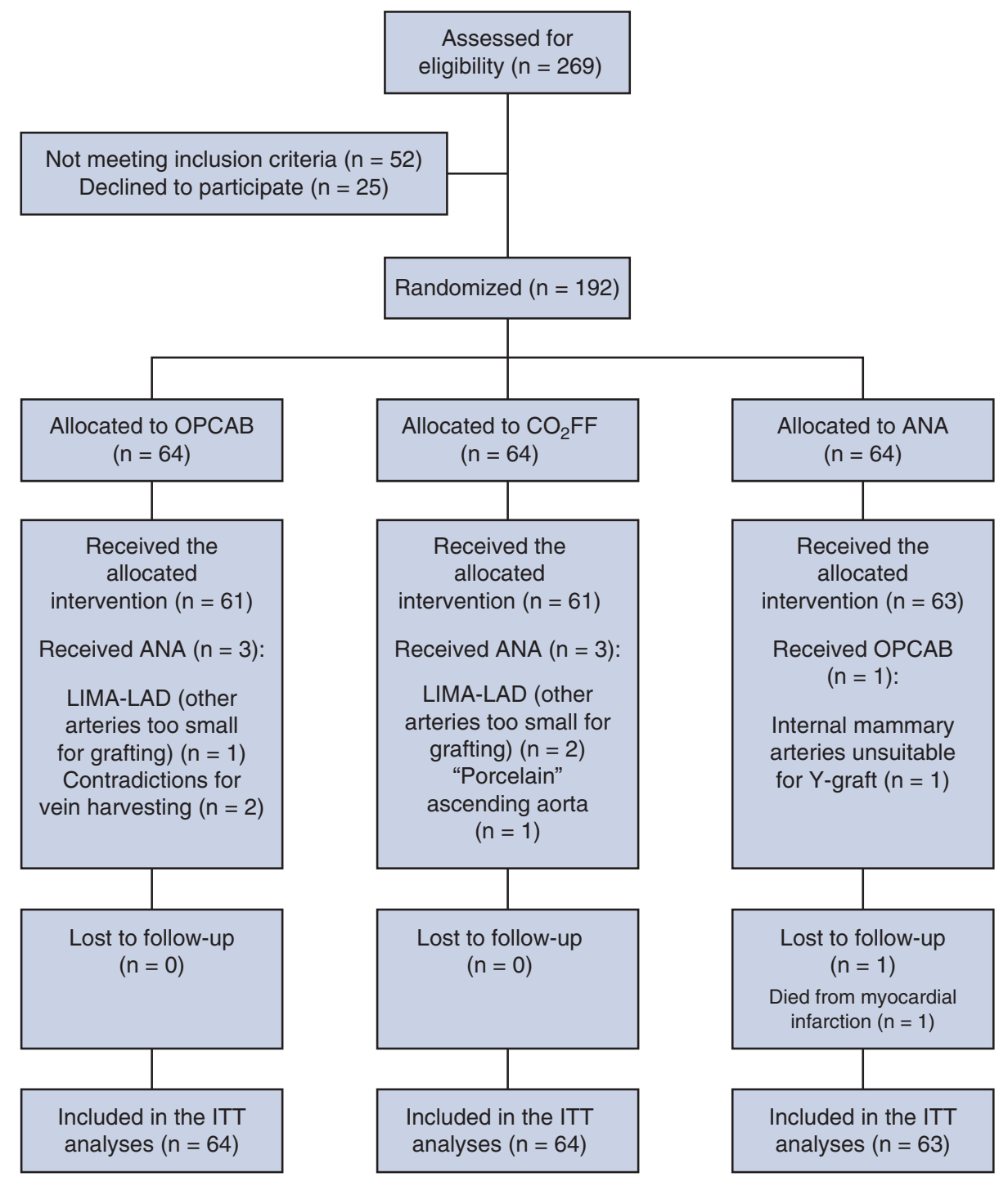

FIGURE 1. Participants' flow through the trial. $O P C A B$, Off-pump coronary artery bypass surgery; $\mathrm{CO}_{2} \mathrm{FF}$, off-pump coronary artery bypass surgery using carbon dioxide surgical field flooding; $A N A$, anaortic off-pump coronary artery bypass surgery; LIMA-LAD, left internal mammary artery to left anterior descending artery bypass; $Y$-graft, right internal mammary artery anastomosed onto left internal mammary artery allowing for complete arterial revascularization; ITT, intention to treat. 
TABLE 1. Preoperative characteristics

\begin{tabular}{|c|c|c|c|}
\hline Characteristic & OPCAB & $\mathrm{CO}_{2} \mathrm{FF}$ & ANA \\
\hline \multicolumn{4}{|l|}{ Preoperative data for risk evaluation by the EuroSCORE II* } \\
\hline Age, $y$, mean $\pm S D$ or median (IQR) & $66.3 \pm 9.0$ & $64.0(61.0-69.0)$ & $65.2 \pm 7.7$ \\
\hline Female sex, n $(\%)$ & $14(21.9)$ & $22(34.4)$ & $15(23.4)$ \\
\hline \multicolumn{4}{|l|}{ Renal impairment, $\mathrm{n}(\%)$} \\
\hline Normal (creatinine clearance $>85 \mathrm{~mL} / \mathrm{min}$ ) & $43(67.2)$ & $35(54.7)$ & $37(57.8)$ \\
\hline Moderate (creatinine clearance $50-85 \mathrm{~mL} / \mathrm{min}$ ) & $18(28.1)$ & $26(40.6)$ & $25(39.1)$ \\
\hline Severe (creatinine clearance $<50 \mathrm{~mL} / \mathrm{min}$ ) & $3(4.7)$ & $2(3.1)$ & $2(3.1)$ \\
\hline Dialysis & $0(0.0)$ & $1(1.6)$ & $0(0.0)$ \\
\hline Extracardiac arteriopathy, n (\%) & $6(9.4)$ & $5(7.8)$ & $4(6.3)$ \\
\hline Chronic lung disease, $\mathrm{n}(\%)$ & $5(7.8)$ & $3(4.7)$ & $2(3.1)$ \\
\hline Diabetes mellitus (type 1 or 2 ) insulin-dependent, $\mathrm{n}(\%)$ & $17(26.6)$ & $17(26.6)$ & $14(21.9)$ \\
\hline \multicolumn{4}{|l|}{ New York Heart Association class, n (\%) } \\
\hline I & $6(9.4)$ & $3(4.7)$ & $5(7.8)$ \\
\hline II & $10(15.6)$ & $13(20.3)$ & $12(18.8)$ \\
\hline III & $3(4.7)$ & $4(6.3)$ & $1(1.6)$ \\
\hline IV & $0(0.0)$ & $0(0.0)$ & $0(0.0)$ \\
\hline Canadian Cardiovascular Society class 4 angina, n (\%) & $8(12.5)$ & $4(6.3)$ & $10(15.6)$ \\
\hline \multicolumn{4}{|l|}{ Left ventricular function, $\mathrm{n}(\%)$} \\
\hline Good $(>50 \%)$ & 49 (76.6) & $54(84.4)$ & $55(85.9)$ \\
\hline Moderate $(31 \%-50 \%)$ & $15(23.4)$ & $10(15.6)$ & $9(14.1)$ \\
\hline Poor or very poor $(\leq 30 \%)$ & $0(0.0)$ & $0(0.0)$ & $0(0.0)$ \\
\hline Recent myocardial infarction $(\leq 90 \mathrm{~d}), \mathrm{n}(\%)$ & $22(34.4)$ & $22(34.4)$ & $22(34.4)$ \\
\hline Logistic EuroSCORE II for operative risk, \%, median (IQR) & $0.9(0.7-1.2)$ & $0.9(0.7-1.1)$ & $0.8(0.6-1.2)$ \\
\hline \multicolumn{4}{|l|}{ Other selected preoperative data } \\
\hline Atrial fibrillation, $\mathrm{n}(\%)$ & $1(1.6)$ & $4(6.3)$ & $5(7.8)$ \\
\hline Body mass index, $\mathrm{kg} / \mathrm{m}^{2}$ mean $\pm \mathrm{SD}$ or median (IQR) & $28.2 \pm 4.2$ & $28.7(26.9-31.7)$ & $27.8 \pm 4.5$ \\
\hline Diabetes mellitus (type 2) non-insulin-dependent, $\mathrm{n}(\%)$ & $6(9.4)$ & $10(15.6)$ & $7(10.9)$ \\
\hline Education, y, median (IQR) & $12.0(12.0-12.0)$ & $12.0(12.0-12.0)$ & $12.0(11.5-12.0)$ \\
\hline Hyperlipidemia, n (\%) & $43(67.2)$ & $30(46.9)$ & $35(54.7)$ \\
\hline Hypertension, $\mathrm{n}(\%)$ & $52(81.3)$ & $55(85.9)$ & $53(82.8)$ \\
\hline Previous myocardial infarction $(>90 \mathrm{~d}), \mathrm{n}(\%)$ & $12(18.8)$ & $12(18.8)$ & $14(21.9)$ \\
\hline Smoker within past year, $\mathrm{n}(\%)$ & $28(43.8)$ & $27(42.2)$ & $28(43.8)$ \\
\hline
\end{tabular}

There were no statistically significant differences among the study arms. $O P C A B$, off-pump coronary artery bypass surgery; $C O_{2} F F$, off-pump coronary artery bypass surgery using carbon dioxide surgical field flooding; ANA, anaortic off-pump coronary artery bypass surgery; EuroSCORE II, European System for Cardiac Operative Risk Evaluation model II; $S D$, standard deviation; $I Q R$, interquartile range. "Data not included were covered by the study's exclusion criteria.

\section{Randomization}

Participants were randomized at a 1:1:1 ratio to the 3 study arms according to a computer-generated list of random numbers. This sequence was prepared by an independent statistician, sealed in sequentially numbered envelopes, and stored in the operating block. Immediately before the first incision, the surgical team chief opened the next consecutively numbered envelope to identify which intervention to perform. The final decision on the type of intervention was based on patient safety and was made by the surgical team chief after intraoperative assessment.

\section{Blinding}

Investigators and patients were blinded to study arm allocation. However, in trials involving total arterial revascularization, there is an inherent potential for unblinding because of the absence of vein harvest wounds after ANA. Considering this risk, patients were asked not to disclose any information about the surgery to the research staff. In addition, clinical staff were instructed to cover the patients' legs during each neuropsychiatric assessment.

\section{Statistical Methods}

Categorical variables were reported as numbers and percentages and compared among the 3 study arms with the $\chi^{2}$ test for multiple groups. Continuous variables were reported as mean \pm standard deviation or median and interquartile range if skewed and compared among the 3 study arms with 1-way analysis of variance or the Kruskall-Wallis test as appropriate. Multiple comparison tests were conducted when a $P$ value of $<.025$ was obtained. $P<.025$ was considered to indicate statistical significance. Odds ratios (ORs) and 95\% confidence intervals (CIs) between the control arm and each of the study arms were calculated for outcome data that showed statistically significant differences. All analyses were performed with the $\mathrm{R}$ version 3.4 .3 (R Project for Statistical Computing, Vienna, Austria).

\section{RESULTS \\ Participant Flow}

Between March 2017 and June 2018, a total of 269 patients scheduled for elective OPCAB were screened for study participation; of these, 192 were recruited and assigned at random to the OPCAB arm $(\mathrm{n}=64), \mathrm{CO}_{2} \mathrm{FF}$ $\operatorname{arm}(n=64)$, or ANA arm $(n=64)$. Three patients in the OPCAB arm, 3 patients in the $\mathrm{CO}_{2} \mathrm{FF}$ arm, and 1 patient in the ANA arm did not receive the allocated intervention. Figure 1 shows the participants' flow through the trial. 
TABLE 2. Selected intraoperative and postoperative data

\begin{tabular}{|c|c|c|c|}
\hline Parameter & OPCAB & $\mathrm{CO}_{2} \mathrm{FF}$ & ANA \\
\hline \multicolumn{4}{|l|}{ Intraoperative data } \\
\hline Time of surgery, min, mean \pm SD or median (IQR) & $214.5 \pm 46.0$ & $220.3 \pm 50.7$ & $235.0(205.0-285.0)$ \\
\hline Distal anastomoses, n, median (IQR) & $3(2-3)$ & $3(2-3)$ & $3.0(2-3)$ \\
\hline Nadir mean arterial pressure at surgery, $\mathrm{mm} \mathrm{Hg}$, mean $\pm \mathrm{SD}$ or median (IQR) & $54.9 \pm 6.6$ & $52.5(46.7-56.7) \dagger$ & $55.33(50.0-60.3)$ \\
\hline Nadir hematocrit during surgery, $\%$, mean $\pm \mathrm{SD}$ & $33.5 \pm 4.3$ & $32.7 \pm 4.9$ & $33.3 \pm 4.5$ \\
\hline Nadir hemoglobin during surgery, g/dL, mean \pm SD or median (IQR) & $11.4 \pm 1.4$ & $10.8(9.9-11.6)$ & $11.4 \pm 1.5$ \\
\hline Red cell concentrate transfusion during surgery, $\mathrm{n}(\%)$ & $11(17.2)$ & $17(26.5)$ & $12(18.8)$ \\
\hline \multicolumn{4}{|l|}{ Postoperative data } \\
\hline Time of intubation, min, median (IQR) & $595.0(507.5-740.0)$ & $630.0(515.0-747.5)$ & $705.0(562.5-807.5)$ \\
\hline Nadir mean arterial pressure in ICU, $\mathrm{mm} \mathrm{Hg}$, mean $\pm \mathrm{SD}$ or median (IQR) & $66.7(60.0-73.3)$ & $65.5 \pm 11.4$ & $70.0(60.0-76.7)$ \\
\hline Inotropes in ICU, $\mathrm{n}(\%)$ & $22(34.4)$ & $31(38.4)$ & $27(42.2)$ \\
\hline Nadir hematocrit in ICU, $\%$, mean $\pm \mathrm{SD}$ or median (IQR) & $30.8(27.9-34.4)$ & $29.4 \pm 4.4 \dagger$ & $31.2 \pm 4.2$ \\
\hline Nadir hemoglobin in ICU, g/dL, mean \pm SD or median (IQR) & $10.3 \pm 1.3$ & $9.6(8.7-10.7)$ & $11.1 \pm 5.0$ \\
\hline Red cell concentrate transfusion in ICU, $\mathrm{n}(\%)$ & $11(17.2)$ & $18(28.1)$ & $12(18.8)$ \\
\hline Nadir blood glucose in ICU, mg/dL, mean \pm SD & $102.5 \pm 22.4$ & $99.5 \pm 22.7$ & $100.0 \pm 19.4$ \\
\hline Antipsychotics in ICU, n (\%) & $10(15.6)$ & $15(23.4)$ & $3(4.7)^{*}$ \\
\hline Prolonged ICU stay $(>48 \mathrm{~h}), \mathrm{n}(\%)$ & $8(12.5)$ & $14(21.9)$ & $10(15.9)$ \\
\hline Prolonged hospitalization $(>7 \mathrm{~d}), \mathrm{n}(\%)$ & 19 (29.7) & 19 (29.7) & $14(21.9)$ \\
\hline
\end{tabular}

$O P C A B$, Off-pump coronary artery bypass surgery; $\mathrm{CO}_{2} F F$, off-pump coronary artery bypass surgery using carbon dioxide surgical field flooding; $A N A$ anaortic off-pump coronary artery bypass surgery; $S D$, standard deviation; $I Q R$, interquartile range; $I C U$, intensive care unit. "Differences in surgery time and the use of antipsychotics between ANA and $\mathrm{OPCAB}$ were statistically significant. $\dagger$ Differences in nadir mean arterial pressure during surgery and nadir hematocrit in ICU between $\mathrm{CO}_{2} \mathrm{FF}$ and $\mathrm{OPCAB}$ as well as between $\mathrm{CO}_{2} \mathrm{FF}$ and ANA were statistically significant.

There were no cases of unblinding. One patient in ANA arm died from myocardial infarction and was not included in the final intention-to-treat analyses of primary and secondary outcomes. All other participants completed postoperative assessments with no missing data.

\section{Baseline Data}

There were no statistically significant differences in perioperative variables between the ANA and OPCAB arms, with the exception of longer duration of ANA surgery and less frequent postoperative use of antipsychotics after ANA (Tables 1 and 2). However, none of these differences can explain the superior outcomes in ANA arm. In addition, there were no statistically significant differences in baseline mood and neurocognitive tests between the study arms. Our multivariable analysis is described in Appendix E2.

\section{Delirium Outcomes}

PD occurred in 23 of 64 patients $(35.9 \%)$ treated with OPCAB, compared with 21 of 64 patients $(32.8 \%)$ treated with $\mathrm{CO}_{2} \mathrm{FF}$ and 8 of 63 patients $(12.5 \%)$ treated with ANA (Figure 2, Table 3). This was a statistically significant association $\left(\chi^{2}(2, \mathrm{~N}=191)=10.17 ; P=.006\right)$. Post hoc tests revealed that the incidence of PD in ANA arm differed from that in the OPCAB arm (OR, $0.26 ; 95 \% \mathrm{CI}$, $0.09-0.68 ; P=.002)$. Per protocol analysis showed similar results in the incidence of PD: 23 of 61 patients $(37.7 \%)$ treated with $\mathrm{OPCAB}$, compared with 21 of 61 $(34.4 \%)$ treated with $\mathrm{CO}_{2} \mathrm{FF}$ and 8 of $62(12.9 \%)$ treated with ANA, a statistically significant association $\left(\chi^{2}(2, \mathrm{~N}=185)=11.04 ; P=.004\right)$. Post hoc tests revealed that the incidence of PD in the ANA arm differed from that in the OPCAB arm (OR, 0.25; 95\% CI, 0.09-0.65; $P=.002)$.

Additional (not preplanned) examination of delirium motoric subtype distribution exposed a statistically significant difference in the between-arm incidence of hypoactive $\operatorname{PD}\left(\chi^{2}(2, \mathrm{~N}=191)=9.04 ; P=.01\right)$ (Table 3). Post hoc tests revealed that the incidence of hypoactive $\mathrm{PD}$ in the ANA arm differed from that in the OPCAB arm (OR, 0.17; 95\% CI, 0.03-0.63; $P=.003)$.

\section{Neurocognitive Outcomes}

ePOCD occurred in 22 of 64 patients $(34.4 \%)$ treated with OPCAB, compared with 18 of $64(28.1 \%)$ treated with $\mathrm{CO}_{2} \mathrm{FF}$ and 6 of $63(9.5 \%)$ treated with ANA (Figure 2, Table 3), a statistically significant association $\left(\chi^{2}(2, \mathrm{~N}=191)=11.58 ; P=.003\right)$. Post hoc tests revealed that the incidence of ePOCD in the ANA arm differed from that in the OPCAB arm (OR, 0.20; 95\% CI, 0.06-0.58; $P<.001)$. Per protocol analysis showed similar results regarding the incidence of ePOCD: 22 of 61 patients $(36.1 \%)$ treated with $\mathrm{OPCAB}$, compared with 17 of 61 $(27.9 \%)$ treated with $\mathrm{CO}_{2} \mathrm{FF}$ and 6 of $62(9.7 \%)$ treated with ANA, a statistically significant association $\left(\chi^{2}(2, \mathrm{~N}=185)=12.16 ; P=.002\right)$. Post hoc tests revealed that the incidence of ePOCD in the ANA arm differed from that in the OPCAB arm (OR, 0.19; 95\% CI, 0.06-0.55; $P<.001)$. Additional analyses of neuropsychological test results are available in Appendix E3. 


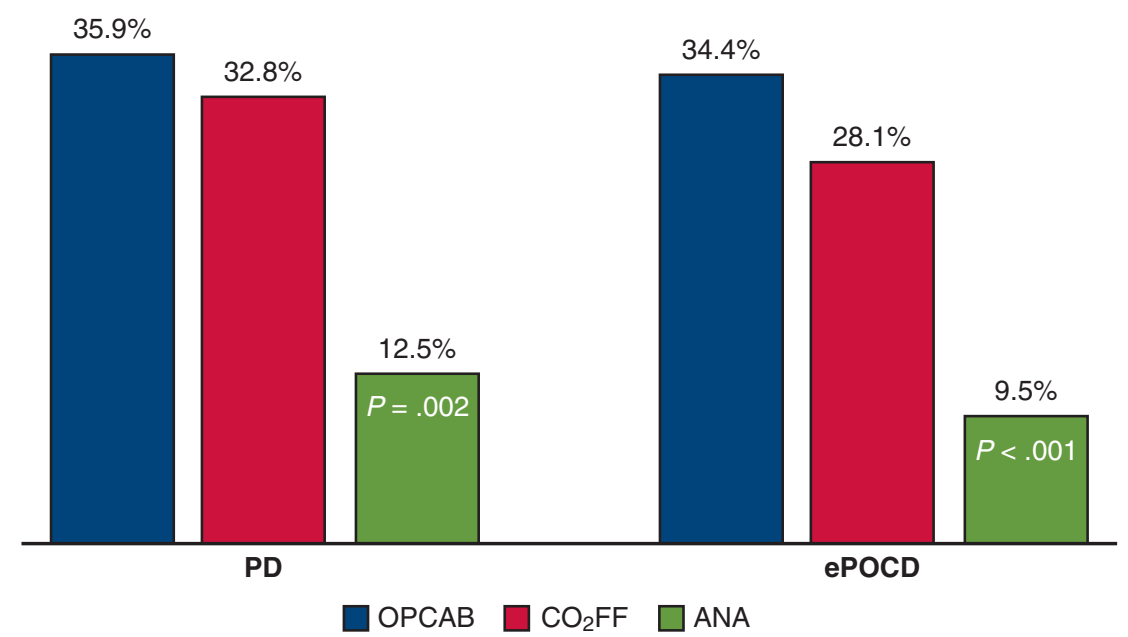

FIGURE 2. Performing anaortic off-pump coronary artery bypass grafting ( $A N A)$ results in a 3 -fold reduction in the incidence of postoperative delirium $(P D)$ and early postoperative cognitive dysfunction $(e P O C D)$ as compared with off-pump coronary artery bypass grafting with vein grafts $(O P C A B)$, whereas performing off-pump coronary artery bypass with vein grafts using $\mathrm{CO}_{2}$ surgical field flooding $\left(\mathrm{CO}_{2} F F\right)$ is inconsequential in this regard.

\section{DISCUSSION}

The results of this trial suggest that performing ANA significantly decreases the incidence of PD and ePOCD in patients undergoing $\mathrm{OPCAB}$, whereas using $\mathrm{CO}_{2} \mathrm{FF}$ is inconsequential in this regard. It should be noted that in the ANA arm, the PD reduction is primarily in the hypoactive motoric subtype, a condition characterized by apathy, slowed mentation and movement. Importantly, PD with these features is the easiest to overlook by medical staff, and thus, like ePOCD, it is recognized primarily during specific clinical research. ${ }^{4}$ As a result, a significant advantage of using the ANA technique for PD and ePOCD prevention might not be readily noticeable.

Manipulation of the ascending aorta, such as using a site-biting clamp to perform proximal vein anastomoses during $\mathrm{OPCAB}$, causes embolic showers that can be seen on transcranial Doppler. ${ }^{14}$ The total omission of this maneuver in ANA has been shown to reduce cerebrovascular accidents in the scarce research on this topic. ${ }^{15,16}$ while its effect on neuropsychiatric complications has been tested

TABLE 3. Outcomes and adverse events

\begin{tabular}{|c|c|c|c|c|c|c|}
\hline Outcome/event & ОРСАВ & $\mathrm{CO}_{2} \mathrm{FF}$ & ANA & $P$ value & $\begin{array}{l}\text { OPCAB-CO } \mathrm{O}_{2} \mathrm{OPCAB}, \\
\text { OR }(95 \% \mathrm{CI}) ; P \text { value }\end{array}$ & $\begin{array}{l}\text { OPCAB-anOPCAB, } \\
\text { OR }(95 \% \text { CI }) ; P \text { value }\end{array}$ \\
\hline \multicolumn{7}{|l|}{ Primary outcome } \\
\hline ePOCD, n (\%) & $22(34.4)$ & $18(28.1)$ & $6(9.5)$ & .003 & $0.75,(0.33-1.69) ; .45$ & $0.20(0.06-0.56) ;<.001$ \\
\hline \multicolumn{7}{|l|}{ Secondary outcomes } \\
\hline Overall incidence of PD, $\mathrm{n}(\%)$ & $23(35.9)$ & $21(32.8)$ & $8(12.5)$ & .006 & $0.87(0.39-1.93) ; .71$ & $0.26(0.09-0.68) ; .002$ \\
\hline \multicolumn{7}{|l|}{ Motoric subtype of PD, $n(\%)$} \\
\hline Hyperactive & $7(10.9)$ & $6(9.4)$ & $3(4.8)$ & .43 & & \\
\hline Hypoactive & $15(23.4)$ & $12(18.8)$ & $3(4.8)$ & .011 & $0.76(0.29-1.93) ; .52$ & 0.17 (0.03-0.63);.003 \\
\hline Mixed & $1(1.6)$ & $3(4.7)$ & $2(3.2)$ & .60 & & \\
\hline Stroke, n (\%) & $2(3.1)$ & $1(1.6)$ & $0(0.0)$ & .36 & & \\
\hline Transient ischemic attack, $\mathrm{n}(\%)$ & $0(0.0)$ & $1(1.6)$ & $0(0.0)$ & .37 & & \\
\hline \multicolumn{7}{|l|}{ Adverse in-hospital events } \\
\hline All-cause mortality, n (\%) & $0(0.0)$ & $1(1.6)$ & $1(1.6)$ & .60 & & \\
\hline Major bleeding, n (\%) & $1(1.6)$ & $3(4.7)$ & $0(0.0)$ & .17 & & \\
\hline Myocardial infarction, n (\%) & $1(1.6)$ & $1(1.6)$ & $1(1.6)$ & .44 & & \\
\hline Repeat revascularization, $\mathrm{n}(\%)^{*}$ & $3(4.7)$ & $5(7.8)$ & $1(1.6)$ & .25 & & \\
\hline Deep sternal wound infection, $\mathrm{n}(\%)$ & $2(3.1)$ & $0(0.0)$ & $1(1.6)$ & .36 & & \\
\hline Atrial fibrillation, n (\%) & $8(12.5)$ & $8(12.5)$ & $11(17.2)$ & .67 & & \\
\hline Acute kidney injury, n (\%) & $9(14.1)$ & $9(14.1)$ & $5(7.8)$ & .45 & & \\
\hline
\end{tabular}

$\overline{O P C A B}$, off-pump coronary artery bypass surgery; $\mathrm{CO}_{2} \mathrm{FF}$, off-pump coronary artery bypass surgery using $\mathrm{CO}_{2}$ surgical field flooding; $A N A$, anaortic off-pump coronary artery bypass surgery; $O R$, odds ratio; $C I$, confidence interval; $e P O C D$, early postoperative cognitive dysfunction; $P D$, postoperative delirium. ${ }^{*}$ All repeat revascularizations were by percutaneous coronary intervention. 


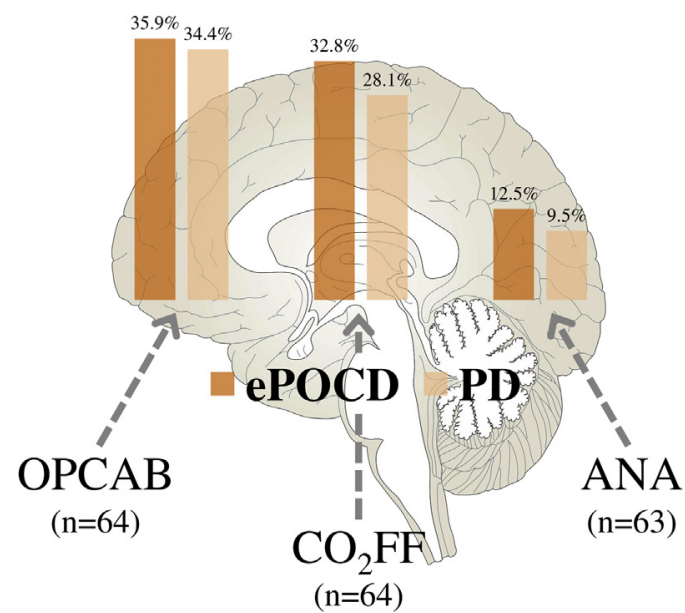

FIGURE 3. Performing anaortic off-pump coronary artery bypass grafting (ANA) results in a 3 -fold reduction in the incidence of postoperative delirium $(P D)$ and early postoperative cognitive dysfunction $(e P O C D)$ as compared with off-pump coronary artery bypass grafting with vein grafts $(O P C A B)$ while performing off-pump coronary artery bypass with vein grafts using $\mathrm{CO}_{2}$ surgical field flooding $\left(\mathrm{CO}_{2} \mathrm{FF}\right)$ is inconsequential in this regard.

only in this trial's pilot study. ${ }^{2}$ It is very important that favorable results afforded by ANA not only apply to relatively rarely occurring postoperative stroke, but also cover ubiquitous PD and ePOCD, which meaningfully impact everyday postoperative clinical practice.

Although the ANA technique can reduce the number of solid emboli that are exceptionally dangerous to the central nervous system, formation of gaseous emboli remains a threat. This hazard may possibly be mitigated by the use

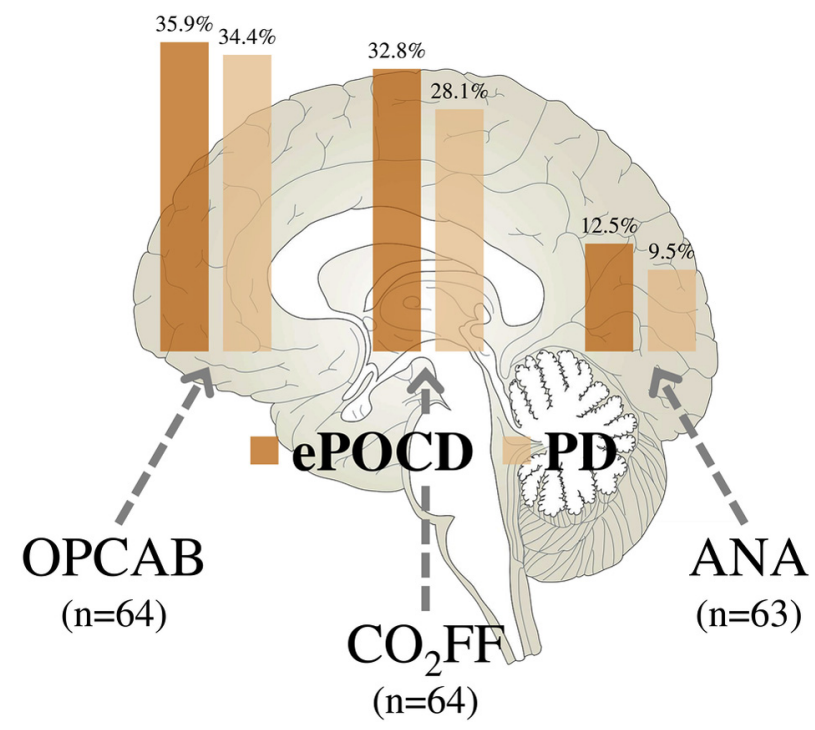

VIDEO 1. A video summary of the trial's impact on patients' postoperative recovery. Video available at: https://www.jtcvs.org/article/ S0022-5223(19)32091-4/fulltext. of $\mathrm{CO}_{2} \mathrm{FF}$ to displace air in the surgical field. Carbon dioxide $\left(\mathrm{CO}_{2}\right)$ does not form any bubbles, because it is 25 times more soluble in blood than air and is rapidly discharged from the body through breathing. Although it remains relatively underused in OPCAB, $\mathrm{CO}_{2}$ has been used in cardiac operations since the 1950s. There have been consistent reports of its neuroprotective qualities in heart valve surgery, none of which focused on OPCAB, however. ${ }^{17}$ Considering the results of the present trial, it is possible that OPCAB is not sufficiently invasive to benefit from the effect of $\mathrm{CO}_{2} \mathrm{FF}$.

\section{Generalizability}

Similar results can be expected in other treatment centers; however, they may be dependent on individual surgeon competence in ANA technique. Importantly, the CANON operators were highly skilled in this method, as underscored by the fact that only a single crossover occurred in the ANA arm. Thus, the outcomes of this relatively demanding procedure were not affected by surgeons' inexperience.

\section{Limitations}

This trial's limitations include its single-center design and the inability to blind the surgical team. In addition, although planned in the protocol, magnetic resonance imaging was not used in this study. This entailed a change in sample size, because it was originally calculated for the radiologic outcome. Finally, future research of this type should consider performing longitudinal follow-ups because the negative effects of PD and PPOCD may extend beyond the immediate postoperative period. Some data associate PD with lower health-related quality of life even at 18 months after surgery, while ePOCD has been correlated with loss of social function and independence, resulting in increased reliance on social welfare payments and earlier withdraw from the labor market. ${ }^{18,19}$

\section{CONCLUSIONS}

Performing ANA significantly decreases the incidence of PD and $\mathrm{ePOCD}$ compared with OPCAB with vein grafts, whereas $\mathrm{CO}_{2} \mathrm{FF}$ is inconsequential in this regard (Figure 3 and Video 1). These results may reflect decreased delivery of an embolic load to the brain in ANA and have practical applicability in daily practice to possibly significantly improve clinical outcomes.

\section{Conflict of Interest Statement}

Authors have nothing to disclose with regard to commercial support.

We thank Professor David Taggart for his cooperation and contributions to this trial. 


\section{References}

1. Zhang WY, Wu WL, Gu JJ, Sun Y, Ye XF, Qiu WJ, et al. Risk factors fo postoperative delirium in patients after coronary artery bypass grafting: a prospective cohort study. J Crit Care. 2015;30:606-12.

2. Szwed K, Pawliszak W, Anisimowicz L, Buciński A, Borkowska A. Short-term outcome of attention and executive functions from aorta no-touch and traditional off-pump coronary artery bypass surgery. World J Biol Psychiatry. 2014;15: 397-403.

3. Evans AS, Weiner MM, Arora RC, Chung I, Deshpande R, Varghese R, et al Current approach to diagnosis and treatment of delirium after cardiac surgery. Ann Card Anaesth. 2016;19:328-37.

4. American Psychiatric Association. Diagnostic and Statistical Manual of Mental Disorders (DSM-5). 5th ed. Washington, DC: American Psychiatric Publishing; 2013.

5. Indja B, Seco M, Seamark R, Kaplan J, Bannon PG, Grieve SM, et al Neurocognitive and psychiatric issues post cardiac surgery. Heart Lung Circ. 2017;26:779-85

6. Inouye SK. Delirium in older persons. N Engl J Med. 2006;354:1157-65.

7. Szwed K, Pawliszak W, Serafin Z, Kowalewski M, Tomczyk R, Perlinski D, et al. CArbon dioxide surgical field flooding and aortic NO-touch off-pump coronary artery bypass grafting to reduce Neurological injuries after surgical coronary revascularisation (CANON): protocol for a randomised, controlled, investigator and patient blinded single-centre superiority trial with three parallel arms. $B M J$ Open. 2017;7:e016785.

8. Chou R, Gordon DB, de Leon-Casasola OA, Rosenberg JM, Bickler S, Brennan T, et al. Management of postoperative pain: a clinical practice guideline from the American Pain Society, the American Society of Regional Anesthesia and Pain Medicine, and the American Society of Anesthesiologists' Committee on Regional Anesthesia, Executive Committee, and Administrative Council. J Pain. 2016;17:131-57.

9. Murkin JM, Newman SP, Stump DA, Blumenthal JA. Statement of consensus on assessment of neurobehavioral outcomes after cardiac surgery. Ann Thorac Surg. 1995:59:1289-95.

10. Ely EW, Inouye SK, Bernard GR, Gordon S, Francis J, May L, et al. Delirium in mechanically ventilated patients: validity and reliability of the confusion assessment method for the intensive care unit (CAM-ICU). JAMA. 2001;286 2703-10.

11. Munk L, Andersen G, Møller AM. Post-anaesthetic emergence delirium in adults: incidence, predictors and consequences. Acta Anaesthesiol Scand. 2016;60:1059-66

12. Sessler CN, Gosnell MS, Grap MJ, Brophy GM, O'Neal PV, Keane KA, et al. The Richmond Agitation-Sedation Scale: validity and reliability in adult intensive care unit patients. Am J Respir Crit Care Med. 2002;166:1338-44.

13. Peterson JF, Pun BT, Dittus RS, Thomason JW, Jackson JC, Shintani AK, et al. Delirium and its motoric subtypes: a study of 614 critically ill patients. J Am Geriatr Soc. 2006;54:479-84.

14. Falk V. Stay off-pump and do not touch the aorta! Eur Heart J. 2010;31 278-80.

15. Pawliszak W, Kowalewski M, Raffa GM, Malvindi PG, Kowalkowska ME Szwed KA, et al. Cerebrovascular events after no-touch off-pump coronary artery bypass grafting, conventional side-clamp off-pump coronary artery bypass, and proximal anastomotic devices: a meta-analysis. J Am Heart Assoc. 2016;5 $\mathrm{e} 002802$.

16. Albert A, Ennker J, Hegazy Y, Ullrich S, Petrov G, Akhyari P, et al Implementation of the aortic no-touch technique to reduce stroke after off-pump coronary surgery. J Thorac Cardiovasc Surg. 2018;156:544-54.e4.

17. Ganguly G, Dixit V, Patrikar S, Venkatraman R, Gorthi SP, Tiwari N. Carbon dioxide insufflation and neurocognitive outcome of open heart surgery. Asian Cardiovasc Thorac Ann. 2015;23:774-80.

18. Loponen P, Luther M, Wistbacka JO, Nissinen J, Sintonen H, Huhtala H, et al. Postoperative delirium and health related quality of life after coronary artery bypass grafting. Scand Cardiovasc J. 2008;42:337-44.

19. Steinmetz J, Christensen KB, Lund T, Lohse N, Rasmussen LS, ISPOCD Group. Long-term consequences of postoperative cognitive dysfunction. Anesthesiology. 2009;110:548-55

Key Words: cardiac surgery, coronary artery disease surgery, neurologic events, neuropsychiatric complications, delirium, postoperative cognitive dysfunction 
APPENDIX E1. GRAFTING PROCEDURE COMPLETED IN THE CONTROL ARM: OFF-PUMP CORONARY ARTERY BYPASS WITH VEIN GRAFTS (OPCAB)

All procedures were done via a median sternotomy without the use of or conversion to cardiopulmonary bypass. The heart was exposed using Starfish heart positioning device (Medtronic, Minneapolis, Minn) or deep pericardial traction sutures (Lima stitch). Proximal anastomoses were performed using a site-biting clamp. Distal anastomoses were performed using an Octopus coronary stabilizer (Medtronic) and a "soft" bulldog clamp. All left anterior descending (LAD) artery lesions were bypassed with a skeletonized left internal mammary artery to LAD (LIMALAD) graft. Other lesions were bypassed using saphenous vein grafts. The quality of anastomoses was assessed by intraoperative transit time flow measurements.

\section{GRAFTING PROCEDURE COMPLETED IN THE FIRST STUDY ARM: OFF-PUMP CORONARY ARTERY BYPASS WITH TOTAL ARTERIAL REVASCULARIZATION (ANA)}

All procedures were done via a median sternotomy without the use of or conversion to cardiopulmonary bypass. The heart was exposed using a Starfish heart positioning device (Medtronic) or deep pericardial traction sutures (Lima stitch). Distal anastomoses were performed using an Octopus coronary stabilizer (Medtronic) and a "soft" bulldog clamp. Complete arterial revascularization was achieved with bilateral skeletonized internal mammary arteries, using the Y-grafting technique when necessary. No other vascular conduits were used. The quality of the anastomoses was assessed by intraoperative transit time flow measurements.

\section{GRAFTING PROCEDURE COMPLETED IN THE SECOND STUDY ARM: OFF-PUMP CORONARY ARTERY BYPASS WITH VEIN GRAFTS USING CARBON DIOXIDE SURGICAL FIELD FLOODING $\left(\mathrm{CO}_{2} \mathrm{FF}\right)$}

All procedures were done via a median sternotomy without the use of or conversion to cardiopulmonary bypass. In this study arm, the chest cavity was insufflated with $\mathrm{CO}_{2}$ at a flow of $>5 \mathrm{~L} / \mathrm{min}$ during the entire procedure. The heart was exposed using a Starfish heart positioning device (Medtronic) or deep pericardial traction sutures (Lima stitch). Proximal anastomoses were performed using a side-biting clamp. Distal anastomoses were performed using an Octopus coronary stabilizer (Medtronic) and a "soft" bulldog clamp. All LAD lesions were bypassed with skeletonized LIMALAD grafts. Other lesions were bypassed using saphenous vein grafts. The quality of the anastomoses was assessed by intraoperative transit time flow measurements.

\section{APPENDIX E2.}

Potential confounders were selected in 2 steps. In the first step, they were identified based on the information obtained from research literature. Thus, patient age, years of education, smoking status, logistic EuroSCORE, diagnosis of diabetes and/or atrial fibrillation, and red cell concentrate (RCC) transfusions during surgery were chosen as possible risk factors for postoperative neuropsychiatric complications. In the second step, univariable analyses were used to identify other potential covariates for the prediction of PD and ePOCD. Variables with a $P$ value of $<.20$ were chosen.

\section{MULTIVARIABLE ANALYSIS OF PD}

The following categorical variables were entered into the model: ANA arm, Canadian Cardiovascular Society class 4, diabetes, atrial fibrillation, hyperlipidemia, New York Heart Association (NYHA) class I, NYHA class III, RCC transfusion during surgery, RCC transfusion in intensive care unit (ICU), and smoker within the past year. The following continuous variables were added: age, body mass index (BMI), logistic EuroSCORE, Mini Mental State Exam score, and years of education.

Multivariable analysis was performed with multiple logistic regression analysis. The stepwise forward method was applied to build the model. The following factors were significantly and independently related to PD: ANA arm, RCC transfusions in ICU, BMI, and age (Table E1). The bootstrap was used for internal model validation. The discrimination ability of the model was indicated by an area under the receiver operating characteristic curve of 0.75. The Hosmer-Lemeshow goodness-of-fit test indicated that the model fit the data well $(P=.13)$.

\section{MULTIVARIABLE ANALYSIS OF EPOCD}

The following categorical variables were entered into the model: acute kidney injury, ANA arm, Canadian Cardiovascular Society class 4, diabetes, diabetes on insulin, atrial fibrillation, hyperlipidemia, NYHA classification class III, recent myocardial infarction, RCC transfusion during surgery, RCC transfusion in the ICU, smoker within the past year, and sternal wound infection. The following continuous variables were also added into the model: age, BMI, logistic EuroSCORE, and years of education.

Multivariable analysis was performed with multiple logistic regression analysis. The stepwise forward method was applied to build the model. The following factors were significantly and independently related to ePOCD: ANA arm, smoker within the past year, diabetes on insulin, and RCC transfusion in the ICU (Table E2). The bootstrap was used for internal model validation. The discrimination ability of the model was indicated by an area under the receiver operating characteristic curve of 0.74 . The 
Hosmer-Lemeshow goodness-of-fit test indicated that the model fit the data well $(P=.44)$.

\section{APPENDIX E3}

Although performing ANA was associated with decreased impairment in most of the neuropsychological tests, in 3 of these tests this effect did not reach statistical significance (Table E3). While exceptional resilience of the examined cognitive domains cannot be ruled out, a more likely explanation for this result can be provided. Analysis of preoperative data (Table E4) reveals that approximately one-half of the patients were unable to complete the first Trail Making Test, part B, and that most of them had low initial scores in Digit Span Test-Forward and Backward. Thus, their outcomes could have been affected by the so-called "floor effect," meaning that poor preoperative measurements of these instruments possibly concealed some postoperative deterioration, mainly in the OPCAB arm. Moreover, scoring $<5$ in the initial Digit Span tests meant that even the smallest deterioration in follow-up met the applied criterion of cognitive impairment. Thus, this instrument might have been too sensitive, qualifying too many patients as cognitively impaired, mainly in the ANA arm. These observations emphasize the need for optimal psychometric battery and preinclusion dementia screening to avoid distorting ePOCD research results. 
TABLE E1. Significant variables included in the model

\begin{tabular}{lccc}
\hline \multicolumn{1}{c}{ Variable } & $\boldsymbol{\beta}$ & OR $(\mathbf{9 5} \% \mathbf{C I})$ & $\boldsymbol{P}$ value \\
\hline ANA arm & 0.44 & $0.27(0.11-0.64)$ & .003 \\
RCC transfusion in ICU & 0.40 & $2.57(1.17-5.65)$ & .019 \\
BMI & 0.04 & $1.01(1.01-1.19)$ & .021 \\
Age & 0.03 & $1.06(1.00-1.12)$ & .048 \\
Constant & 2.32 & $0.001(0.00-0.07)$ & .002 \\
\hline
\end{tabular}

$O R$, Odds ratio; $C I$, confidence interval; $A N A$, anaortic off-pump coronary artery bypass surgery; $R C C$, red cell concentrate; $I C U$, intensive care unit; $B M I$, body mass index.
TABLE E2. Significant variables included in the model

\begin{tabular}{lccc}
\hline \multicolumn{1}{c}{ Variable } & $\boldsymbol{\beta}$ & OR $(\mathbf{9 5} \% \mathbf{C I})$ & $\boldsymbol{P}$ value \\
\hline ANA arm & 0.49 & $0.22(0.08-0.57)$ & .002 \\
Smoker within past year & 0.36 & $2.14(1.03-4.45)$ & .043 \\
Diabetes on insulin & 0.51 & $4.69(1.72-12.77)$ & .003 \\
RCC transfusion in ICU & 0.42 & $2.36(1.04-5.35)$ & .039 \\
Constant & 0.32 & $0.21(0.11-0.39)$ & $<.001$ \\
\hline
\end{tabular}

$O R$, Odds ratio; $C I$, confidence interval; $A N A$, anaortic off-pump coronary artery bypass surgery; $R C C$, red cell concentrate; $I C U$, intensive care unit. 
TABLE E3. Incidence of cognitive impairment related to specific test

\begin{tabular}{|c|c|c|c|c|}
\hline Test & Tested domains & OРCAB & $\mathrm{CO}_{2} \mathrm{FF}$ & ANA \\
\hline Stroop Test, part A, n (\%) & Speed of processing & 19 (29.7) & $18(28.1)$ & $7(11.1)^{*}$ \\
\hline Stroop Test, part B, n (\%) & Attention, automaticity, parallel distributed processing & 19 (29.7) & $17(26.6)$ & $6(9.5)^{*}$ \\
\hline Trail Making Test, part A, n (\%) & Psychomotor speed & $22(34.4)$ & $26(40.6)$ & $9(14.3)^{*}$ \\
\hline Trail Making Test, part B, n (\%) & Selective attention, shifting ability & 19 (29.7) & $21(32.8)$ & $13(20.6)$ \\
\hline Digit Span Test-forward, n (\%) & Auditory attention, short-term retention & $17(26.6)$ & $13(20.3)$ & $14(22.2)$ \\
\hline Digit Span Test- backward, n (\%) & Verbal working memory & $26(40.6)$ & $21(32.8)$ & $19(30.2)$ \\
\hline $\begin{array}{l}\text { Rey Auditory Verbal Learning Test, } \\
\text { trials I-V combined, n }(\%)\end{array}$ & Immediate memory function, learning & $11(17.2)$ & $6(9.4)$ & $1(1.6)^{*}$ \\
\hline $\begin{array}{l}\text { Rey Auditory Verbal Learning Test, } \\
\text { delayed recall, } \mathrm{n}(\%)\end{array}$ & Delayed memory function & $18(28.1)$ & $11(17.2)$ & $4(6.4)^{*}$ \\
\hline
\end{tabular}

Additional (not preplanned) analyses showed that patients treated with ANA exhibited a significantly lower prevalence of cognitive impairment in 5 out of 8 neuropsychological tests. Cognitive impairment was defined as decline from preoperative performance of $>20 \%$. $O P C A B$, Off-pump coronary artery bypass surgery; $C \mathrm{O}_{2} \mathrm{FF}$, off-pump coronary artery bypass surgery using $\mathrm{CO}_{2}$ surgical field flooding; ANA, anaortic off-pump coronary artery bypass surgery. "The differences between Stroop Test part A, Stroop Test part B, Trail Making Test part A, Rey Auditory Verbal Learning Test trials I-V combined, and Rey Auditory Verbal Learning Test - delayed recall between ANA and OPCAB were statistically significant.

TABLE E4. Preoperative results of mood and neurocognitive tests

\begin{tabular}{|c|c|c|c|}
\hline Test & ОРСАВ & $\mathrm{CO}_{2} \mathrm{FF}$ & ANA \\
\hline $\begin{array}{l}\text { Hospital Anxiety and Depression Scale- Anxiety, } \\
\text { mean } \pm \text { SD or median (IQR) }\end{array}$ & $6.7 \pm 3.3$ & $7.5 \pm 3.1$ & $7.0(5.0-8.0)$ \\
\hline $\begin{array}{l}\text { Hospital Anxiety and Depression Scale- Depression, } \\
\text { median (IQR) }\end{array}$ & $4.0(2.0-7.0)$ & $4.0(2.0-6.3)$ & $4.0(2.0-6.0)$ \\
\hline Mini-Mental State Exam, median (IQR) & $29.0(28.0-30.0)$ & $30.0(28.0-30.0)$ & $29.0(28.0-30.0)$ \\
\hline Stroop Test part A, median (IQR) & $28.5(25.0-33.0)$ & $28.0(23.0-32.0)$ & $28.5(25.0-33.0)$ \\
\hline Stroop Test part B, median (IQR) & $83.0(66.0-96.5)$ & $71.0(61.0-82.0)$ & $74.5(63.0-89.5)$ \\
\hline Stroop Test part $\mathrm{B} \geq 20$ errors, $\mathrm{n}(\%)$ & $8(12.5)$ & $4(6.3)$ & $8(12.5)$ \\
\hline Trail Making Test, part A, median (IQR) & $42.5(32.0-55.3)$ & $37.0(28.8-45.3)$ & $39.5(32.0-53.0)$ \\
\hline Trail Making Test, part B, median (IQR) & $93.5(72.5-131.8)$ & $84.0(69.0-100.0)$ & $89.0(72.0-126.0)$ \\
\hline Trail Making Test, part B, >300 s, n (\%) & $38(59.4)$ & $27(42.2)$ & $33(51.6)$ \\
\hline Digit Span Test-forward, median (IQR) & $4.0(4.0-5.0)$ & $4.0(4.0-6.0)$ & $4.0(3.8-5.0)$ \\
\hline Digit Span Test-backward, median (IQR) & $4.0(3.0-5.0)$ & $4.0(3.0-4.0)$ & $4.0(3.0-5.0)$ \\
\hline $\begin{array}{l}\text { Rey Auditory Verbal Learning Test, trials I-V, combined score, } \\
\text { mean } \pm \text { SD or median (IQR) }\end{array}$ & $33.2 \pm 9.0$ & $34.0 \pm 7.3$ & $32.0(25.8-39.0)$ \\
\hline $\begin{array}{l}\text { Rey Auditory Verbal Learning Test, delayed recall, } \\
\text { mean } \pm \text { SD or median (IQR) }\end{array}$ & $6.4 \pm 2.7$ & $6.9 \pm 2.6$ & $6.0(5.0-8.3)$ \\
\hline
\end{tabular}

There were no statistically significant differences among the study arms. $O P C A B$, Off-pump coronary artery bypass surgery; $C O_{2} F F$, off-pump coronary artery bypass surgery using $\mathrm{CO}_{2}$ surgical field flooding; $A N A$, anaortic off-pump coronary artery bypass surgery; $S D$, standard deviation; $I Q R$, interquartile range. 